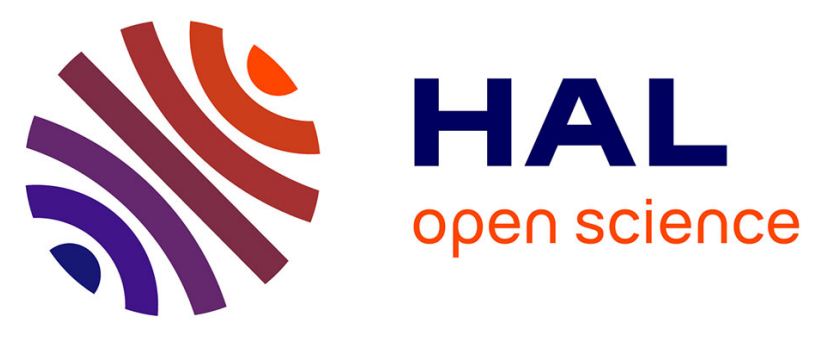

\title{
Combination of breast imaging parameters obtained from 18F-FDG PET and CT scan can improve the prediction of breast-conserving surgery after neoadjuvant chemotherapy in luminal/HER2-negative breast cancer
}

Mathieu Grapin, Charles Coutant, Jean-Marc Riedinger, Sylvain Ladoire, François Brunotte, Alexandre Cochet, Olivier Humbert

\section{- To cite this version:}

Mathieu Grapin, Charles Coutant, Jean-Marc Riedinger, Sylvain Ladoire, François Brunotte, et al.. Combination of breast imaging parameters obtained from 18F-FDG PET and CT scan can improve the prediction of breast-conserving surgery after neoadjuvant chemotherapy in luminal/HER2-negative breast cancer. European Journal of Radiology, 2019, 113, pp.81-88. 10.1016/j.ejrad.2019.02.005 . hal-03352867

\author{
HAL Id: hal-03352867 \\ https://hal.science/hal-03352867
}

Submitted on 22 Oct 2021

HAL is a multi-disciplinary open access archive for the deposit and dissemination of scientific research documents, whether they are published or not. The documents may come from teaching and research institutions in France or abroad, or from public or private research centers.
L'archive ouverte pluridisciplinaire HAL, est destinée au dépôt et à la diffusion de documents scientifiques de niveau recherche, publiés ou non, émanant des établissements d'enseignement et de recherche français ou étrangers, des laboratoires publics ou privés.

\section{(ㄷ)(1) $\$$}

Distributed under a Creative Commons Attribution - NonCommerciall 4.0 International 


\section{Combination of breast imaging parameters obtained from 18F-FDG PET and CT scan} can improve the prediction of breast-conserving surgery after neoadjuvant chemotherapy in luminal/HER2-negative breast cancer.

Mathieu Grapin $(\mathrm{MSc})^{1}$; Charles Coutant $(\mathrm{MD}, \mathrm{PhD})^{2}$; Jean-Marc Riedinger (PharmD) $)^{1,3}$; Sylvain Ladoire $(\mathrm{MD}, \mathrm{PhD})^{4}$, François Brunotte $(\mathrm{MD}, \mathrm{PhD})^{5}$; Alexandre Cochet $(\mathrm{MD}, \mathrm{PhD})^{1,5,6}$; Olivier Humbert $(\mathrm{MD}, \mathrm{PhD})^{7,8}$

${ }^{1}$ Department of Nuclear Medicine, Centre Georges-François Leclerc, Dijon, France;

${ }^{2}$ Department of Surgery, Centre Georges-François Leclerc, Dijon, France;

${ }^{3}$ Department of Biology and Pathology, Centre Georges-François Leclerc, Dijon, France;

${ }^{4}$ Department of Medical Oncology, Centre Georges-François Leclerc, Dijon, France;

${ }^{5}$ LE2I, Arts et Métiers, University of Bourgogne Franche-Comté, Dijon, France

${ }^{6}$ Imaging Department, Dijon University Hospital, Dijon, France;

${ }^{7}$ Department of Nuclear Medicine, Centre Antoine-Lacassagne, Nice, France;

${ }^{8}$ TIRO-UMR E 4320, University of Nice-Sophia-Antipolis, France

\section{Corresponding author or request for reprints: Mathieu GRAPIN}

Service de radiothérapie

Centre Georges-François Leclerc

1 rue Professeur Marion

BP 77980

21079 DIJON Cedex - France

Fax number: +33 (0)3 45348097 / Telephone number: +33 (0)3 80737518 / MathieuGR@aol.com

This research did not receive any specific grant from funding agencies in the public, commercial, or not-for-profit sectors. Declarations of interest: none. All authors have approved the final article. 


\title{
BLINDED MANUSCRIPT
}

Combination of breast imaging parameters obtained from 18F-FDG PET and CT scan can improve the prediction of breast-conserving surgery after neoadjuvant chemotherapy in luminal/HER2-negative breast cancer.

\begin{abstract}
INTRODUCTION: The luminal/Human Epidermal growth factor Receptor 2 (HER2) negative subtype of breast cancer has low chemo-sensitivity. When neoadjuvant chemotherapy (NAC) is indicated in this subtype, before a possible breast-conserving surgery (BCS), it is more reasonable to target tumor shrinkage than complete pathological tumor response. We aimed to identify breast and tumor ${ }^{18}$ Fluoro-deoxy-glucose $\left({ }^{18} \mathrm{~F}-\mathrm{FDG}\right)$ PET-CT scan imaging features for the early prediction of BCS after NAC in luminal/HER2 negative subtypes of breast cancer.

MATERIAL AND METHODS: Seventy-seven consecutive women with luminal/HER2-negative breast cancer for whom BCS was initially not feasible and NAC was prescribed, to decrease tumor size before surgery, were included retrospectively. An ${ }^{18}$ F-FDG PET-CT scan exam was performed before and after the first course of NAC.

RESULTS: After NAC, 36\% (28/77) of women had a mastectomy and 64\% (49/77) underwent BCS. Patients with a mastectomy had lower total breast volume $\left(\mathrm{BV}_{\text {total }}\right)(\mathrm{p}=0.002)$, lower decrease in $\Delta$ metabolic tumor volume $(\Delta \mathrm{MTV})(\mathrm{p}=0.03)$ and lower $\operatorname{SUV}_{\max 2}(\mathrm{p}=0.05)$. Using ROC Curve analyses to define the optimal predictive threshold of $\mathrm{BV}_{\text {total }}\left(496 \mathrm{~cm}^{3}\right)$ and $\Delta$ MTV $(-17.1 \%), 3$ subgroups of women with different odds of BCS after treatment were identified $(p=0.001)$ : low, medium and high probability groups (respectively $29 \%, 62 \%$ and $82 \%$ ).

CONCLUSIONS: For patients with Luminal/HER2 negative breast cancer, the combination of the imaging features of the tumor and the mammary gland, obtained with ${ }^{18}$ F-FDG PET-CT at baseline and after the first cycle of NAC, may allow the physician to evaluate the probability of BCS.
\end{abstract}

\section{List of abbreviations:}

${ }^{18}$ F-FDG: ${ }^{18}$ Fluoro-deoxy-glucose

BCS: Breast Conserving Surgery

$\mathrm{BV}_{\text {Total: }}$ Total Breast Volume

ER: Estrogen Receptor

HER2: Human Epidermal growth factor Receptor 2

HR: Hormone receptor

MTV: Metabolic Tumor Volume

NAC: Neoadjuvant Chemotherapy

pCR: pathological Complete Response

PR: Progesterone Receptor

ROC: Receiver Operating Curve

SBR: Scarff-Bloom-Richardson

SUV: Standard Uptake Value

TLG: Total Lesion Glycolysis

TNBC: Triple Negative Breast Cancer

US scan: UltraSound scan 


\section{INTRODUCTION}

Neoadjuvant chemotherapy (NAC) is a safe and effective therapeutic approach for women with a large primary breast tumor for whom a mastectomy is initially recommended. It offers the advantage of down staging the disease before surgery, potentially reducing its extent. The main clinical benefit of NAC is an increase in the rate of breast-conserving surgery (BCS) [1,2]. NAC does not change a patient's oncologic outcome compared with a mastectomy followed by adjuvant chemotherapy [3], but studies have demonstrated that a pathologic complete response (pCR) in both breast and nodes is a surrogate marker for better outcomes [4-6]. Thus, pCR has become a crucial end-point in the neoadjuvant setting [5]. However, breast cancer is composed of different biological entities. More than half of the women with breast cancer present the luminal/Human Epidermal Growth Factor Receptor 2 (HER2) negative subtype, defined by the expression of hormonal receptors (HR) but no over-expression of the human HER2, which corresponds to the luminal subtype [7]. Compared with other subtypes, it has a more favorable outcome despite lower chemo-sensitivity [8]. Pathologic complete response is rarely achieved in this subtype, and its prognostic value is debatable [5,9-13]. Consequently, tumor shrinkage sufficient for BCS is a more reasonable aim than $\mathrm{pCR}$ in the luminal/HER2-negative subtype. Because the use of NAC for this subtype frequently challenged, there is a need for predictive biomarkers to optimize prescription. Tumor expression of Ki-67 is helpful, but not sufficient [14]. The early metabolic response, evaluated with ${ }^{18}$ Fluoro-deoxy-glucose $\left({ }^{18} \mathrm{~F}\right.$-FDG) PET-CT, accurately predicts pCR in triple negative breast cancer (TNBC) and HER2-positive subtypes [15-17]. However, studies have failed to demonstrate the value of ${ }^{18} \mathrm{~F}$-FDG PET to predict pCR in the luminal breast cancer subtype [1820]. The aim of the present study was to identify, for the luminal/HER2-negative breast cancer subtype, early metabolic and morphologic ${ }^{18}$ FDG PET-CT imaging features predictive of BCS after NAC.

\section{MATERIAL AND METHODS}

Patients and study design

From November 2006 to July 2015, consecutive women referred to our institution for newly diagnosed stage IA to IIIA luminal/HER2-negative breast cancer (defined as hormonal receptorpositive, no HER2 over-expression) were retrospectively included in an on-going ancillary study of prospective current-care protocol in our institution. The inclusion criteria were: BCS was deemed not feasible on initial consultation (high tumor volume/breast volume ratio especially if it was a tumor of the inferior quadrants or retro-areolar) and decision to treat with NAC in order to decrease tumor size and potentially allow BCS after neoadjuvant treatment. For the surgeon there was not any objective clinical criterion of favorable tumor volume/breast volume ratio. The exclusion criteria were: NAC was not administrated with the intention of BCS (inflammatory or multifocal breast lesions), mastectomy was planned independently of tumor response to NAC (patient's desire, BRCA mutation), women under 18 years old or pregnant, women unwilling to undergo the two ${ }^{18}$ F-FDG PET-CT exams, high blood glucose level ( $\left.>9 \mathrm{mmol} / \mathrm{l}\right)$ before PET exams, or metastases on baseline PET. The medical team documented the non-opposition of the patient in source document and in the notice of information provided to the patient. This population overlaps those of previous articles published by our team [18,21].

Baseline clinical characteristics included age, menopausal status, tumor size and lymph node involvement evaluated on US scan. Lymph node involvement on US scan was confirmed by biopsy. Baseline histological characteristics, evaluated on the pre-treatment core needle biopsy, included histological type, tumor grading using the modified Scarff-Bloom-Richardson (SBR) system, architectural differentiation, nuclear polymorphism and number of mitosis. The molecular markers examined included Estrogen Receptor (ER) status, Progesterone Receptor (PR) status, and over-expression of HER 2. 
Women received one of two possible treatment regimens, either a sequential intravenous chemotherapy with 5-Fluorouracile $500 \mathrm{mg} / \mathrm{m}^{2}$, Epirubicine 75 or $100 \mathrm{mg} / \mathrm{m}^{2}$ and Cyclophosphamide $500 \mathrm{mg} / \mathrm{m}^{2}$ (FEC 100, 3 courses: one course every 3 weeks) followed by taxanes (docetaxel $100 \mathrm{mg} / \mathrm{m}^{2}$ for 3 courses: one course every 3 weeks or paclitaxel $80 \mathrm{mg} / \mathrm{m}^{2}$ for 3 courses: one injection weekly for 9 weeks).

${ }^{18}$ Fluoro-deoxy-glucose PET-CT exams were performed for baseline staging, and after the first course of NAC to evaluate tumor response.

Within one month after the last course of NAC, each patient was scheduled for an ultrasound scan (US), in some cases for a MRI and were examined by their surgeon to evaluate tumor response. The surgeon then decided whether the patient should undergo BCS or a mastectomy. The following parameters rather directed the surgeon towards a BCS: low tumor volume/breast volume ratio, tumor of the external quadrants and concentric tumor response on the MRI. There was not any objective cut off for breast size or tumor size. If BCS was followed by a salvage mastectomy (whatever the reason, including incomplete microscopic resection), it was considered a mastectomy for our study. A pathologist examined the resected specimens to evaluate the surgical margin (clear/positive/close) and the pathological tumor response. Histopathological analysis Tumor samples were collected by needle core biopsy before the NAC. The specimens were fixed on buffered formalin, embedded in paraffin and cut in 4- $\mu \mathrm{m}$ thick sections with a microtome. IHC was performed with an indirect immunoperoxidase method using antibodies directed against HER2 oncoprotein, ER and PR (HER2: rabbit monoclonal prediluted antibody 4B5; ER: rabbit monoclonal prediluted antibody SP1; PR: rabbit monoclonal prediluted antibody 1E2, all Ventana Medical Systems, Tucson, AZ, USA;). ER and PR status were considered positive if tumor staining showed at least $10 \%$ positive cells. HER2 status was graded according to the HercepTest scoring system. Invasive tumors with scores of $3+$ were considered positive. In case of $2+$ scores, Fluorescence In Situ Hybridization (FISH) was performed, using the dual color HER2 and CEN17 probes (ZytoLight, SPEC HER2/CEN17 Dual ColorProbe Kit, ZytoVision GmbH, Bremerhaven, Germany). HER2 amplification was defined, according to ASCO/CAP criteria, by a ratio of HER2/CEN17 > 2. Tumor resection was considered as complete if there were clear margins of at least $2 \mathrm{~mm}$ for ductal carcinoma in situ and no invasion of surgical section slices for invasive cancer. Pathological complete response was defined as no residual invasive cancer in the breast and nodes (ypT0/is ypN0)[5].

\section{${ }^{18}$ F-FDG PET-CT exams}

The first ${ }^{18}$ F-FDG PET-CT was performed at baseline. Two different PET-CT imaging systems were used: a Gemini GXL PET-CT scanner from November 2006 to December 2010, and a Gemini TF PET-CT scanner from December 2010 to July 2015 (Philips Medical Systems, Eindhoven, The Netherlands). Patients were instructed to fast for at least $6 \mathrm{~h}$ before the intravenous injection of 5 $\mathrm{MBq} / \mathrm{kg}$ of ${ }^{18} \mathrm{~F}-\mathrm{FDG}$ for Gemini GXL studies and $3 \mathrm{MBq} / \mathrm{kg}$ for Gemini TF studies. Emission and transmission scans from the brain to mid-thigh were acquired $60 \mathrm{~min}$ later. Scans restricted to the chest with patients in the prone position were started 90 min after the injection of ${ }^{18}$ F-FDG. Emission data were corrected for dead time, random and scatter coincidences, and attenuation before reconstruction with the 3D-RAMLA (GEMINI GXL) or 3D OSEM (GEMINI TF) iterative algorithm methods. The second ${ }^{18}$ F-FDG PET-CT was done just before the second course of NAC: a chest scan was completed 90 minutes after the injection of ${ }^{18}$ F-FDG. For each patient, the same imaging system, ${ }^{18} \mathrm{~F}-\mathrm{FDG}$ activity, time from injection to acquisition, and reconstruction parameters were used for baseline and post-treatment studies to obtain good intra-subject standardization. The image voxel counts were calibrated to activity concentration $(\mathrm{Bq} / \mathrm{ml})$ and decay corrected using the time of tracer injection as the reference.

On the chest-restricted baseline PET acquisiton, the whole homolateral mammary gland was delineated on transaxial consecutive CT slices to calculate total Breast Volume (BVtotal) $(\mathrm{cm} 3)$. The primary breast tumor was manually delineated on the baseline and interim PET studies, using a visual method for tumor metabolic delineation on PET images. The metabolic tumor contour obtained was then checked on the CT slices and adjusted to the morphologic edge of the breast lesion if needed. Two operators worked complementarily to record these data (a senior nuclear doctor and a resident), without overlapping. 
The maximum Standardized Uptake Value $\left(\mathrm{SUV}_{\max }\right)$, the mean $\mathrm{SUV}\left(\mathrm{SUV}_{\text {mean }}\right)$, Metabolic Tumor Volume (MTV), and Total Lesion Glycolysis $\left(T L G=S V_{\text {mean }} \times\right.$ MTV) of the primary tumor were calculated at baseline and interim exams and measured on chest prone scan. Baseline $\mathrm{MTV}_{1} / \mathrm{BV}_{\text {total }}$ ratio and $\mathrm{MTV}_{2} / \mathrm{BV}_{\text {total }}$ ratio were reported. Measured $\mathrm{SUV}_{\max }$ were systematically corrected for Body Surface Area (BSA) and glycaemia, as detailed in our previous studies [16,18]. The metabolic response between baseline and interim PET were calculated using theses formulas:

$$
\begin{aligned}
& \Delta \mathrm{SUV}_{\max }(\%)=100 \times\left(\mathrm{SUV}_{\max 2}-\mathrm{SUV}_{\max 1}\right) / \mathrm{SUV}_{\max 1} \\
& \Delta \mathrm{SUV}_{\text {mean }}(\%)=100 \times\left(\mathrm{SUV}_{\text {mean2}}-\mathrm{SUV}_{\text {mean } 1}\right) / \mathrm{SUV}_{\text {mean } 1} \\
& \Delta \mathrm{MTV}(\%)=100 \times\left(\mathrm{MTV}_{2}-\mathrm{MTV}_{1}\right) / \mathrm{MTV}_{1} \\
& \Delta \mathrm{TLG}(\%)=100 \times\left(\mathrm{TLG}_{2}-\mathrm{TLG}_{1}\right) / \mathrm{TLG}_{1} \\
& \text { Statistical analysis }
\end{aligned}
$$

Statistical analysis was performed with the use of WinSTAT software (Microsoft, Redmond, Washington, USA) and Systat software (Systat Inc, Evanston, IL). Data were described as frequency (percentage) or mean ( \pm Standard Deviation $(\mathrm{SD})$ ) and median (range). Correlations between ${ }^{18} \mathrm{~F}-\mathrm{FDG}$ PET-CT data and surgery were assessed with the Mann-Whitney test, and associations between qualitative variables and final surgery procedures were evaluated using the chi-square test and fisher test. The optimal cutoff values for continuous variables correlated with the final surgery procedure were determined using receiver operating curve (ROC) analyses. Univariate and multivariate analysis logistic regression analyzes were used to identify predictive factors of BCS. All p-values were twosided and considered significant when below 0.05 .

\section{RESULTS}

\section{Patient characteristics}

Seventy-seven women were included. The patients' clinical and biological characteristics at baseline are shown in Table 1. Median age was 52 years [26-75]. Median tumor size, which was assessed with breast US scan and/or mammogram, was $3.2 \mathrm{~cm}[1.5-7.5]$. US scan results showed that $56 \%$ (43/77) of women had lymph node involvement. Sixty-two percent (47/77) of tumors were SBR II, 87\% (67/77) were invasive ductal carcinoma and the remaining tumors were lobular carcinoma. The median breast volume $\left(\mathrm{BV}_{\text {total }}\right)$ on ${ }^{18} \mathrm{~F}-\mathrm{FDG}$ PET-CT was $540 \mathrm{~cm}^{3}$ [149 - 2150]. The median $\mathrm{SUV}_{\max 1}$ was 5.1 [1.7 - 23.9], median $\mathrm{MTV}_{1}$ was $6.7 \mathrm{~cm}^{3}$ [0,9-57.8], and median $\mathrm{TLG}_{1}$ was 21.3 [1.7 - 486.7]. In terms of tumor metabolic response, median $\Delta \mathrm{SUV}_{\max }$ was $-24 \%$ $[-89-+101]$, median $\Delta$ TLG was $-43 \%[-97-+37]$ and median $\Delta$ MTV was $-30 \%[-87-+18]$. BCS was performed in $64 \%$ (49/77) of the women. Mastectomy was performed in the remaining $36 \%$ (28/77) including 8 salvage mastectomies due to incomplete microscopic resection on BCS.

\section{Relationship between clinico-histopathological and imaging parameters with final surgery}

There was a significant difference of PR status between the BCS and mastectomy subgroups: $75 \%$ of patients (21/28) overexpressed PR in the mastectomy group whereas $92 \%$ of patients $(45 / 49)$ overexpressed PR in BCS group $(\mathrm{p}=0.04)$ (Table 2). There was no significant difference in patient age, tumor size, tumor location, lymph node status, SBR grade, or ER expression, protocol of chemotherapy. The patient with $\mathrm{pCR}$ who was submitted to mastectomy had a tumor residue on US scan by the end of NAC (false positive).

Analysis of imaging features revealed that patients with a mastectomy had lower $\mathrm{BV}_{\text {total }}$ $(\mathrm{p}=0.002)$, lower decrease $\Delta \mathrm{MTV}(\mathrm{p}=0.03)$ and were prone to lower $\mathrm{SUV}_{\max 2}(\mathrm{p}=0.05)($ Table 3). Baseline MTV, TLG, $\mathrm{MTV}_{1} / \mathrm{BV}_{\text {Total }}$ ratio and $\mathrm{MTV} 2 / \mathrm{BV}_{\text {Total }}$ ratio were not significantly associated with the final surgery. In multivariate analysis, the following parameters were associated with a BCS: $\triangle \mathrm{MTV}$ OR $=0.27$ [95\% CI, $0.08-0.87](\mathrm{p}=0.03), \mathrm{SUV} 2_{\max } \mathrm{OR}=3.96$ [95\% CI, $1.27-12.36](\mathrm{p}=0.02)$. These two parameters were at the limit of significance: $\mathrm{BV}_{\text {total }}$ $\mathrm{OR}=3.11$ [95\% CI, $1.00-9.63](\mathrm{p}=0.05)$, positive PR OR = 4.53 [95\% CI, $0.29-22.32$ ]

$(\mathrm{p}=0.06)$. Using ROC curve analysis, the optimal threshold of the different continuous and predictive PET-CT variables were $496 \mathrm{~cm}^{3}$ for $\mathrm{BV}_{\text {Total }}(\mathrm{AUC}=0.71),-17 \%$ for $\triangle \mathrm{MTV}$ and 3.6 for $\mathrm{SUV}_{\max 2}(\mathrm{AUC}=0.65$ and 0.64 , respectively) (Table 4). Focusing on two main predictive factors of BCS ( $\mathrm{BV}_{\text {total }}$ and $\left.\triangle \mathrm{MTV}\right)$, we identified three subgroups of women with significantly different odds of undergoing BCS $(\mathrm{p}<0.001)$ (Table 5): 
High probability of BCS was defined as women with $\mathrm{BV}_{\text {total }}\left(>496 \mathrm{~cm}^{3}\right)$ and good tumor shrinkage ( $\triangle$ MTV $<-17 \%)$ : The probability of BCS in this group was 82\% (28/32 patients) (Figure 1a \& 1b).

Intermediate probability of BCS was defined as women with high $\mathrm{BV}_{\text {total }}\left(>496 \mathrm{~cm}^{3}\right)$ and poor tumor shrinkage $(\triangle \mathrm{MTV} \geq-17 \%)$ or women with low $\mathrm{BV}_{\text {total }}\left(\leq 496 \mathrm{~cm}^{3}\right)$ and good tumor shrinkage $(\triangle \mathrm{MTV}<-17 \%)$. The probability of BCS in this group was $62 \%(16 / 26$ patients).

Low probability of BCS was defined as women with low $\mathrm{BV}_{\text {total }}\left(\leq 496 \mathrm{~cm}^{3}\right)$ and poor tumor shrinkage $(\triangle \mathrm{MTV} \geq-17 \%)$. The probability of BCS in this group was $29 \%$ (5/17 patients) (Figure 2a \& $2 \mathrm{~b}$ ).

\section{DISCUSSION}

Being able to predict at baseline which women with luminal/HER2 negative tumors will have sufficient tumor response for breast preservation is an important clinical issue. The clinical and biological markers in this subtype are not sufficient to accurately determine the indication of NAC at an individual level. The surgeon can weigh clinical parameters such as breast size, tumor location or tumor baseline volume, but these criteria are based on subjective evaluation. Using clinico-pathologic data, Rouzier et al. has prospectively developed nomograms that can be used to predict the probability of residual tumor size and eligibility for breast conservation therapy after NAC [22], but the conception of this nomogram did not take the tumor immuno-histochemical subtype into account and was thus not designed for the specific Luminal/HER2 subtype. This nomogram did not include any imaging data.

Because glucose metabolism is increased in breast cancer, the monitoring of metabolic response with

${ }^{18}$ F-FDG PET has been proposed for the early prediction of pCR $[18,23]$. The accuracy of PET is high in TNBC and HER2 positive subtypes [15-17]. In the Luminal/HER2 negative subtype, previous studies failed to demonstrate its predictive ability. Some authors demonstrated that a near-pCR could be predicted [24], but the prognostic value of near-pCR failed to be demonstrated and is not considered a good clinical end-point [5]

In the present study, we recorded and quantified the morphologic and metabolic PET-CT imaging characteristics before and after the first course of NAC. Most of the patients (86\% in mastectomy group and $94 \%$ in BCS group) received 3 cycles of FEC followed by 3 cycles of taxanes. Thus, the response to taxanes is not evaluated by the design of our study. It has been shown in the adjuvant setting than replacing the last 2 FEC 100 cycles of 6 FEC100 regimen by 4 Taxol does not lead to a discernable DFS or OS advantage [25]. However, in the neoadjuvant setting, anthracycline and taxane-based chemotherapy would give a higher rate of pCR over the anthracycline-based chemotherapy [26]. In our study, almost the same proportion of patients received 3 FEC 100 and 3 taxanes in each group, but the midcourse switch to taxanes is a limit. Contrary to previous studies, we did not try to predict $\mathrm{pCR}$ nor near-pCR, but rather aimed to identify Luminal/HER2 negative patients who were most likely to qualify for breast conservation therapy, which is the main clinical advantage of NAC in this tumor subtype.

Two main predictive imaging parameters of BCS were found:

Breast morphology: women with a $\mathrm{BV}_{\text {Total }}$ over $496 \mathrm{~mL}$, quantified precisely on the baseline CT compound of the PET system, were more likely to have BCS.

Tumor chemosensitivity: positive metabolic response after the $1^{\text {st }}$ cycle of treatment, defined by $\Delta$ MTV $<-17 \%$, was associated with a higher probability of BCS.

We combined these two characteristics to identify three groups of patients with varying odds of undergoing BCS. It is interesting to notice that BCS gradually increases from $29 \%$ in the most unfavorable group (low $\mathrm{BV}_{\text {Total }}$ and poor tumor shrinkage) to $82 \%$ in the most favourable one (high $\mathrm{BV}_{\text {Total }}$ and good tumor shrinkage). Surprisingly, we observed that $\mathrm{SUV}_{\max 2}$ was higher in BCS group (4.3) compared to mastectomy group (3.0). But $\mathrm{SUV}_{\max 2}$ can hardly be compared between these two groups because $\mathrm{SUV}_{\max 1}$ was also higher in the BCS group (5.8 versus 4.3 respectively). In the literature, $\triangle$ MTV was also found to be a significant prognostic factor for pathological response in a population including several breast tumor subtypes $[20,27]$. Groheux et al. also demonstrated a strong correlation between $\triangle \mathrm{MTV}$ and good pathologic response $(-21 \% \pm 31 \%$ in non-responders vs $-57 \% \pm$ $37 \%$ in responders; $\mathrm{P}=0.0002$ ), superior to the correlation with $\Delta \mathrm{SUV}_{\max }$ but lower than those of 
$1 \Delta$ TLG [20]. Among the biologic parameters, negative PR status $(\mathrm{p}=0.04)$ and the luminal B subtype $2 \quad(p=0.02)$ were predictive of a pathologic response.

3 Seung Hyun Son et al. also showed that $\Delta$ MTV was correlated with disease free survival [28]. When surgery is performed as first-line treatment, $\mathrm{BV}_{\text {Total }}$ should be measured in breast cancer because the tumor/BV $\mathrm{B}_{\text {Total }}$ ratio is of significance when evaluating whether BCS is appropriate $[29,30]$. Nevertheless, we are the first study to demonstrate the clinical interest of $\mathrm{BV}_{\text {Total }}$ measurement at baseline to predict final BCS, which remains the main goal of NAC in this setting. The CT component of PET, used at baseline for tumor staging, can accurately measure $\mathrm{BV}_{\text {Total }}$. The $\mathrm{BV}_{\text {Total }}$ threshold to predict BCS was approximately $500 \mathrm{~cm}^{3}$ in our study. It is worth noting that we did not find any predictive value for baseline tumor volume or Tumor/BV $\mathrm{B}_{\text {Total }}$ ratio. Lastly, the manual delineation of tumors on the PET-CT images may be a limitation. Manual segmentation is time consuming, labor intensive and operator-dependent, and the intra- and inter-operator variability of the resulting delineations make this method less precise and reproducible than a fixed threshold [31-34]. Nevertheless, in breast cancer, differentiation of the tumor uptake from the surrounding uptake of the mammary gland is an image segmentation issue that cannot be rigorously addressed using fixed and adaptive threshold-based methodologies. The fixed threshold that we tried for this study (either fixed SUV or specific percentage of $\mathrm{SUV}_{\max }$ ) failed to delineate low FDG-avid and heterogeneous breast tumors; they led to inconsistent tumor volumes. Despite a high inter-reader agreement [31], the literature has demonstrated that fixed thresholds cannot reliably define MTV because of their deterministic and binary nature, as long as tumor uptake is variable, spatially heterogeneous, and dependent on a large number of data acquisition and image reconstruction parameters [32-34]. Adaptive thresholds are likely to provide sufficient accuracy in simple cases, but require precise tuning for a specific scanner, the reconstruction type, and even the size of the patient $[32,34]$. Moreover, fixed thresholds generally make too many simplifying assumptions to be considered for complex situations such as low-contrast lesion with complex shape and heterogeneous uptake [32,34]. Consequently, in the absence of more appropriate segmentation tools such as iterative, stochastic and learning-based thresholding methods, it is assumed that fixed thresholds are to be avoided and manual tumor delineation should be favored $[32,35]$.

There are several possibilities for further study. Firstly, it would be of great interest to develop nomograms including relevant biological biomarkers, such as Ki-67 and imaging parameters to improve accuracy in predicting breast conservation after NAC. Secondly, MRI was not systematically performed and we could therefore not compare PET and MRI for early tumor volume changes. An MRI can provide key data such has the extent of the residual tumor after NAC [36] and is a valuable tool for the surgeon in decision-making following first line treatment. When compared with a mammography and an ultrasound after NAC, the MRI better predicts pathological response [37]. A pre-operative MRI can reduce the rate of tumor-positive resection margins substantially (from 29\% to 16\%) [38]. Currently, no study has demonstrated that an MRI can accurately predict the final conservative surgery in luminal/HER2 negative breast cancers at baseline. ${ }^{18}$ F-FDG PET and MRI could have complementary functions with respectively a high sensibility and a high specificity to predict response to NAC $[39,40]$. If we look further, ${ }^{18} \mathrm{~F}-\mathrm{FDG}$ PET/MRI is a useful method for estimating both morphologic and metabolic tumor volume [41]. Even to estimate breast volume, MRI is highly accurate [42].

In the present study we did not directly correlate MTV with morphologic volume. But previous studies have underlined the discrepancies between these volumes [43]. Indeed, the MTV measured at baseline and after one cycle, only includes the part of the tumor which is "FDG-positive" and, by nature, excludes the part of the tumor morphologic volume with no high glycolytic activity, such as necrosis, fibrosis or scar. The part of the tumor volume is not negligible after the induction of chemotherapy. The MTV represents the dual characteristics of tumor extent, a morphologic characteristic, and the intensity of FDG uptake by tumor tissues, a biological tumor characteristic. Thus, the MTV measured on PET imaging, carry a unique biological information not obtained with conventional morphological imaging such as US scan. For example, ${ }^{18}$ F-FDG-PET imaging can differentiate the viable portion of a heterogeneous tumor from fibrosis or necrotic portions. In future studies, it would be of high interest to assess if early tumor volume changes, measured on functional MRI, could also predict surgical outcome in the neoadjuvant luminal breast cancer setting. A precocious determination of the success percentage of BCS after one course of NAC 
could help to adapt therapeutics; by adding hormonotherapy to chemotherapy [44], changing drug regimen [45], or leading to mastectomy without waiting for the end of the 6 courses of NAC.

\section{CONCLUSIONS}

For patients with Luminal/ HER2 negative breast cancer, the imaging features of both the tumor and the mammary gland, obtained with a ${ }^{18}$ F-FDG PET-CT at baseline and after the first cycle of NAC, may enable the physician to evaluate the probability of final conserving surgery, if confirmed by prospective studies. Imaging data resulting from these techniques could thus help clinicians and breast cancer patients to optimize clinical decision-making. It is likely that the integration of imaging parameters such as $\mathrm{BV}_{\text {Total }}$ and $\triangle \mathrm{MTV}$ in future will improve the accuracy of nomograms in this setting.

\section{REFERENCES}

[1] B.K. Killelea, V.Q. Yang, S. Mougalian, N.R. Horowitz, L. Pusztai, A.B. Chagpar, D.R. Lannin, Neoadjuvant Chemotherapy for Breast Cancer Increases the Rate of Breast Conservation: Results from the National Cancer Database, J. Am. Coll. Surg. 220 (2015) 1063-1069. doi:10.1016/j.jamcollsurg.2015.02.011.

[2] E. Barranger, J. Antomarchi, E. Chamorey, C. Cavrot, B. Flipo, P. Follana, I. Peyrottes, C. Chapellier, J.M. Ferrero, T. Ihrai, Effect of Neoadjuvant Chemotherapy on the Surgical Treatment of Patients With Locally Advanced Breast Cancer Requiring Initial Mastectomy, Clin. Breast Cancer. 15 (2015) e231-e235. doi:10.1016/j.clbc.2015.03.001. [4] D. Mauri, N. Pavlidis, et J. P. A. Ioannidis, « Neoadjuvant Versus Adjuvant Systemic Treatment in Breast Cancer: A Meta-Analysis », J. Natl. Cancer Inst., vol. 97, no 3, p. $188 \square 194$, févr. 2005.

[5] H. M. Kuerer et al., « Clinical course of breast cancer patients with complete pathologic primary tumor and axillary lymph node response to doxorubicin-based neoadjuvant chemotherapy », J. Clin. Oncol., vol. 17, no 2, p. 460-460, 1999. B. Gerber, W. Eiermann, J. Hilfrich, J. Huober, C. Jackisch, M. Kaufmann, G.E. Konecny, C. Denkert, V. Nekljudova, K. Mehta, S. Loibl, Definition and impact of pathologic complete response on prognosis after neoadjuvant chemotherapy in various intrinsic breast cancer subtypes, J. Clin. Oncol. Off. J. Am. Soc. Clin. Oncol. 30 (2012) 1796-1804. doi:10.1200/JCO.2011.38.8595.

[6] F. Penault-Llorca, C. Abrial, I. Raoelfils, A. Cayre, M.-A. Mouret-Reynier, M. Leheurteur, X. Durando, J.-L. Achard, P. Gimbergues, P. Chollet, Comparison of the prognostic significance of Chevallier and Sataloff's pathologic classifications after neoadjuvant chemotherapy of operable breast cancer, Hum. Pathol. 39 (2008) 1221-1228. doi:10.1016/j.humpath.2007.11.019.

50 [7] K. Köninki, M. Tanner, A. Auvinen, J. Isola, HER-2 positive breast cancer: decreasing 51 proportion but stable incidence in Finnish population from 1982 to 2005, Breast Cancer Res. 5211 (2009) R37. 
1 [8] C. Yoo, J.-H. Ahn, K.H. Jung, S.-B. Kim, H.-H. Kim, H.J. Shin, S.H. Ahn, B.H. Son,

2 G. Gong, Impact of immunohistochemistry-based molecular subtype on chemosensitivity and

3 survival in patients with breast cancer following neoadjuvant chemotherapy, J. Breast Cancer. $4 \quad 15$ (2012) 203-210. doi:10.4048/jbc.2012.15.2.203.

5 [9] M. Colleoni, G. Viale, D. Zahrieh, G. Pruneri, O. Gentilini, P. Veronesi, R.D. Gelber,

6 G. Curigliano, R. Torrisi, A. Luini, M. Intra, V. Galimberti, G. Renne, F. Nolè, G. Peruzzotti,

7 A. Goldhirsch, Chemotherapy is more effective in patients with breast cancer not expressing

8 steroid hormone receptors: a study of preoperative treatment, Clin. Cancer Res. Off. J. Am.

9 Assoc. Cancer Res. 10 (2004) 6622-6628. doi:10.1158/1078-0432.CCR-04-0380.

10 [10] R. Bhargava, S. Beriwal, D.J. Dabbs, U. Ozbek, A. Soran, R.R. Johnson, A.M.

Brufsky, B.C. Lembersky, G.M. Ahrendt, Immunohistochemical surrogate markers of breast cancer molecular classes predicts response to neoadjuvant chemotherapy: A single institutional experience with 359 cases, Cancer. 116 (2010) 1431-1439. doi:10.1002/cncr.24876.

[11] R. Rouzier, Breast Cancer Molecular Subtypes Respond Differently to Preoperative Chemotherapy, Clin. Cancer Res. 11 (2005) 5678-5685. doi:10.1158/1078-0432.CCR-042421.

[12] S. Guiu, L. Arnould, F. Bonnetain, C. Dalban, L. Favier, I. Desmoulins, G. Créhange, C. Coutant, P. Fumoleau, B. Coudert, Pathological response and survival after neoadjuvant therapy for breast cancer: A 30-year study, The Breast. 22 (2013) 301-308. doi:10.1016/j.breast.2012.07.012. [13] P. Cortazar, L. Zhang, M. Untch, K. Mehta, J.P. Costantino, N. Wolmark, H. Bonnefoi, D. Cameron, L. Gianni, P. Valagussa, others, Pathological complete response and long-term clinical benefit in breast cancer: the CTNeoBC pooled analysis, The Lancet. 384 (2014) 164-172.

[14] E.H. Lips, L. Mulder, J.J. de Ronde, I. a. M. Mandjes, B.B. Koolen, L.F.A. Wessels, S. Rodenhuis, J. Wesseling, Breast cancer subtyping by immunohistochemistry and histological grade outperforms breast cancer intrinsic subtypes in predicting neoadjuvant chemotherapy response, Breast Cancer Res. Treat. 140 (2013) 63-71. doi:10.1007/s10549013-2620-0.

[15] S. Avril, R.F. Muzic, D. Plecha, B.J. Traughber, S. Vinayak, N. Avril, 18F-FDG PET/CT for Monitoring of Treatment Response in Breast Cancer, J. Nucl. Med. 57 (2016) 34S-39S. doi:10.2967/jnumed.115.157875.

[16] A. Berriolo-Riedinger, C. Touzery, J.-M. Riedinger, M. Toubeau, B. Coudert, L. Arnould, C. Boichot, A. Cochet, P. Fumoleau, F. Brunotte, [18F]FDG-PET predicts complete pathological response of breast cancer to neoadjuvant chemotherapy, Eur. J. Nucl. Med. Mol. Imaging. 34 (2007) 1915-1924. doi:10.1007/s00259-007-0459-5.

[17] O. Humbert, A. Cochet, J.-M. Riedinger, A. Berriolo-Riedinger, L. Arnould, B. Coudert, I. Desmoulins, M. Toubeau, I. Dygai-Cochet, S. Guiu, C. Coutant, P. Fumoleau, F. Brunotte, HER2-positive breast cancer: 18F-FDG PET for early prediction of response to trastuzumab plus taxane-based neoadjuvant chemotherapy, Eur. J. Nucl. Med. Mol. Imaging. 41 (2014) 1525-1533. doi:10.1007/s00259-014-2739-1.

[18] O. Humbert, A. Berriolo-Riedinger, A. Cochet, M. Gauthier, C. Charon-Barra, S. Guiu, I. Desmoulins, M. Toubeau, I. Dygai-Cochet, C. Coutant, P. Fumoleau, F. Brunotte,

45 Prognostic relevance at 5 years of the early monitoring of neoadjuvant chemotherapy using

46 18F-FDG PET in luminal HER2-negative breast cancer, Eur. J. Nucl. Med. Mol. Imaging. 41 47 (2014) 416-427. doi:10.1007/s00259-013-2616-3.

48 [19] H.-J. Im, Y.K. Kim, Y. Kim, J.J. Lee, W.W. Lee, S.E. Kim, Usefulness of Combined 49 Metabolic-Volumetric Indices of 18F-FDG PET/CT for the Early Prediction of Neoadjuvant 
1 Chemotherapy Outcomes in Breast Cancer, Nucl. Med. Mol. Imaging. 47 (2013) 36-43.

2 doi:10.1007/s13139-012-0181-5.

3 [20] D. Groheux, M. Hatt, E. Hindié, S. Giacchetti, P. de Cremoux, J. Lehmann-Che, A.

4 Martineau, M. Marty, C. Cuvier, C. Cheze-Le Rest, A. de Roquancourt, D. Visvikis, M.

5 Espié, Estrogen receptor-positive/human epidermal growth factor receptor 2-negative breast

6 tumors: early prediction of chemosensitivity with (18)F-fluorodeoxyglucose positron

7 emission tomography/computed tomography during neoadjuvant chemotherapy, Cancer. 119

8 (2013) 1960-1968. doi:10.1002/cncr.28020.

9 [21] O. Humbert, A. Berriolo-Riedinger, J.M. Riedinger, B. Coudert, L. Arnould, A.

10 Cochet, C. Loustalot, P. Fumoleau, F. Brunotte, Changes in 18F-FDG tumor metabolism after

11 a first course of neoadjuvant chemotherapy in breast cancer: influence of tumor subtypes,

12 Ann. Oncol. 23 (2012) 2572-2577. doi:10.1093/annonc/mds071.

13 [22] R. Rouzier, L. Pusztai, J.-R. Garbay, S. Delaloge, K.K. Hunt, G.N. Hortobagyi, D.

14 Berry, H.M. Kuerer, Development and validation of nomograms for predicting residual tumor

15 size and the probability of successful conservative surgery with neoadjuvant chemotherapy

16 for breast cancer, Cancer. 107 (2006) 1459-1466. doi:10.1002/cncr.22177.

17 [23] D. Groheux, D. Mankoff, M. Espié, E. Hindié, ${ }^{18}$ F-FDG PET/CT in the early

18 prediction of pathological response in aggressive subtypes of breast cancer: review of the

19 literature and recommendations for use in clinical trials, Eur. J. Nucl. Med. Mol. Imaging. 43

20 (2016) 983-993. doi:10.1007/s00259-015-3295-z.

21 [24] B.B. Koolen, K.E. Pengel, J. Wesseling, W.V. Vogel, M.-J.T.F.D. Vrancken Peeters,

22 A.D. Vincent, K.G.A. Gilhuijs, S. Rodenhuis, E.J.T. Rutgers, R.A. Valdés Olmos, Sequential

23 (18)F-FDG PET/CT for early prediction of complete pathological response in breast and

24 axilla during neoadjuvant chemotherapy, Eur. J. Nucl. Med. Mol. Imaging. 41 (2014) 32-40.

25 doi:10.1007/s00259-013-2515-7.

26 [25] C. Delbaldo, D. Serin, M. Mousseau, S. Greget, B. Audhuy, F. Priou, J.F. Berdah, E.

27 Teissier, P. Laplaige, L. Zelek, E. Quinaux, M. Buyse, P. Piedbois, Association Européenne

28 de Recherche en Oncologie (AERO), A phase III adjuvant randomised trial of 6 cycles of 5-

29 fluorouracil-epirubicine-cyclophosphamide (FEC100) versus 4 FEC 100 followed by 4 Taxol

30 (FEC-T) in node positive breast cancer patients (Trial B2000), Eur. J. Cancer Oxf. Engl.

31 1990. 50 (2014) 23-30. doi:10.1016/j.ejca.2013.09.023.

32 [26] H.G. Dodiya, A.P. Brahmbhatt, P.K. Khatri, A.M. Kaushal, D.G. Vijay, Neoadjuvant

33 chemotherapy in patients with locally advanced breast cancer: A pilot-observational study, J.

34 Cancer Res. Ther. 11 (2015) 612-616. doi:10.4103/0973-1482.146056.

35 [27] E.K. Choi, I.R. Yoo, S.H. Kim, S.Y. Park, J.H. O, B.J. Kang, The value of pre- and

36 post-neoadjuvant chemotherapy F-18 FDG PET/CT scans in breast cancer: comparison with

37 MRI, Acta Radiol. Stockh. Swed. 1987. (2017) 284185117705011.

38 doi:10.1177/0284185117705011.

39 [28] S.H. Hyun, H.K. Ahn, S.H. Moon, Y.S. Cho, Y. Choe, K.-H. Lee, B.-T. Kim, J.Y.

40 Choi, Volume-based metabolic tumor response to neoadjuvant chemotherapy improves

41 outcome prediction in breast cancer, J. Nucl. Med. 55 (2014) 566-566.

42 [29] R.A. Cochrane, P. Valasiadou, A.R.M. Wilson, S.K. Al-Ghazal, R.D. Macmillan,

43 Cosmesis and satisfaction after breast-conserving surgery correlates with the percentage of

44 breast volume excised, Br. J. Surg. 90 (2003) 1505-1509. doi:10.1002/bjs.4344.

45 [30] N.W. Bulstrode, S. Shrotria, Prediction of cosmetic outcome following conservative

46 breast surgery using breast volume measurements, Breast Edinb. Scotl. 10 (2001) 124-126.

47 doi:10.1054/brst.2000.0197.

48 [31] V. Paidpally, G. Mercier, B.A. Shah, S. Senthamizhchelvan, R.M. Subramaniam,

49 Interreader agreement and variability of FDG PET volumetric parameters in human solid

50 tumors, AJR Am. J. Roentgenol. 202 (2014) 406-412. doi:10.2214/AJR.13.10841. 
1 [32] M. Hatt, D. Visvikis, Defining radiotherapy target volumes using 18F-fluoro-deoxy-

2 glucose positron emission tomography/computed tomography: still a Pandora's box?: in

3 regard to Devic et al. (Int J Radiat Oncol Biol Phys 2010), Int. J. Radiat. Oncol. Biol. Phys.

478 (2010) 1605. doi:10.1016/j.ijrobp.2010.08.002.

5 [33] U. Nestle, S. Kremp, A. Schaefer-Schuler, C. Sebastian-Welsch, D. Hellwig, C. Rübe,

6 C.-M. Kirsch, Comparison of different methods for delineation of 18F-FDG PET-positive

7 tissue for target volume definition in radiotherapy of patients with non-Small cell lung cancer,

8 J. Nucl. Med. Off. Publ. Soc. Nucl. Med. 46 (2005) 1342-1348.

9 [34] B. Foster, U. Bagci, A. Mansoor, Z. Xu, D.J. Mollura, A review on segmentation of

10 positron emission tomography images, Comput. Biol. Med. 50 (2014) 76-96.

11 doi:10.1016/j.compbiomed.2014.04.014.

12 [35] K. Wu, Y.C. Ung, D. Hwang, M.S. Tsao, G. Darling, D.E. Maziak, R. Tirona, K. Mah,

13 C.S. Wong, Autocontouring and manual contouring: which is the better method for target

14 delineation using 18F-FDG PET/CT in non-small cell lung cancer?, J. Nucl. Med. Off. Publ.

15 Soc. Nucl. Med. 51 (2010) 1517-1523. doi:10.2967/jnumed.110.077974.

16 [36] A. García-Lallana, I. Antón, R. Saiz-Mendiguren, A. Elizalde, F. Martínez-Regueira,

17 N. Rodríguez-Spiteri, L. Pina, [Using magnetic resonance imaging for staging can change the

18 therapeutic management in patients with breast cancer], Radiologia. 54 (2012) 350-356.

19 doi:10.1016/j.rx.2011.12.007.

20 [37] M.L. Marinovich, P. Macaskill, L. Irwig, F. Sardanelli, E. Mamounas, G. von

21 Minckwitz, V. Guarneri, S.C. Partridge, F.C. Wright, J.H. Choi, M. Bhattacharyya, L.

22 Martincich, E. Yeh, V. Londero, N. Houssami, Agreement between MRI and pathologic

23 breast tumor size after neoadjuvant chemotherapy, and comparison with alternative tests:

24 individual patient data meta-analysis, BMC Cancer. 15 (2015) 662. doi:10.1186/s12885-015-

$25 \quad 1664-4$.

26 [38] I.-M. Obdeijn, M.M.A. Tilanus-Linthorst, S. Spronk, C.H.M. van Deurzen, C. de

27 Monye, M.G.M. Hunink, M.B.E. Menke, Preoperative breast MRI can reduce the rate of

28 tumor-positive resection margins and reoperations in patients undergoing breast-conserving

29 surgery, AJR Am. J. Roentgenol. 200 (2013) 304-310. doi:10.2214/AJR.12.9185.

30 [39] H. Li, L. Yao, P. Jin, L. Hu, X. Li, T. Guo, K. Yang, MRI and PET/CT for evaluation

31 of the pathological response to neoadjuvant chemotherapy in breast cancer: A systematic

32 review and meta-analysis, Breast Edinb. Scotl. 40 (2018) 106-115.

33 doi:10.1016/j.breast.2018.04.018.

34 [40] K. Kitajima, Y. Miyoshi, T. Yamano, S. Odawara, T. Higuchi, K. Yamakado,

35 Assessment of tumor response to neoadjuvant chemotherapy in patients with breast cancer

36 using MRI and FDG-PET/CT-RECIST 1.1 vs. PERCIST 1.0, Nagoya J. Med. Sci. 80 (2018)

37 183-197. doi:10.18999/nagjms.80.2.183.

38 [41] V. Romeo, M. D’Aiuto, G. Frasci, M. Imbriaco, E. Nicolai, Simultaneous PET/MRI

39 assessment of response to cytotoxic and hormone neo-adjuvant chemotherapy in breast

40 cancer: a preliminary report, Med. Oncol. Northwood Lond. Engl. 34 (2017) 18.

41 doi:10.1007/s12032-016-0876-Z.

42 [42] S.B. Choppin, J.S. Wheat, M. Gee, A. Goyal, The accuracy of breast volume

43 measurement methods: A systematic review, The Breast. 28 (2016) 121-129.

44 doi:10.1016/j.breast.2016.05.010.

45 [43] A.C. Paulino, M. Koshy, R. Howell, D. Schuster, L.W. Davis, Comparison of CT- and

46 FDG-PET-defined gross tumor volume in intensity-modulated radiotherapy for head-and-

47 neck cancer, Int. J. Radiat. Oncol. Biol. Phys. 61 (2005) 1385-1392.

48 doi:10.1016/j.ijrobp.2004.08.037.

49 [44] D. Generali, S.P. Corona, L. Pusztai, R. Rouzier, G. Allevi, S. Aguggini, M. Milani,

50 C. Strina, A. Frati, Benefit of the addition of hormone therapy to neoadjuvant anthracycline- 
1 based chemotherapy for breast cancer: comparison of predicted and observed pCR, J. Cancer 2 Res. Clin. Oncol. 144 (2018) 601-606. doi:10.1007/s00432-017-2574-4.

3 [45] T. Zhu, C.L. Liu, Y.F. Zhang, Y.H. Liu, F.P. Xu, J. Zu, G.C. Zhang, X.R. Li, N. Liao, 4 K. Wang, A phase II trial of dose-dense (biweekly) paclitaxel plus carboplatin as neoadjuvant 5 chemotherapy for operable breast cancer, Breast Cancer Res. Treat. 156 (2016) 117-124.

6 doi:10.1007/s10549-016-3735-x.

\section{Legends for figures}

Figure 1a. and 1b. ${ }^{18}$ Fluoro-deoxy-glucose PET-CT images of a 26 year-old woman with high probability of Breast Conserving Surgery $(B C S)$ group: Total Breast Volume $\left(B V_{\text {total }}\right)=1051 \mathrm{~cm}^{3}$ $\left(>496 \mathrm{~cm}^{3}\right)$ and $\triangle$ Metabolic Tumor Volume $(\triangle M T V)=-79.7 \%(<-17 \%)$. After Neoadjuvant Chemotherapy (NAC), she underwent conservation surgery. The MTV was delineated in orange while the $B V_{\text {total }}$ was delineated in blue. Figure la illustrates ${ }^{18} F-F D G$ PET-CT before the first course of $N A C$ (the two images on the left show an axial view, the two images on the right show a sagittal view, the two images on the top show combined PET CT-scan, the two images on the bottom show CT-scan only); figure $1 \mathrm{~b}$ illustrates ${ }^{18} \mathrm{~F}$-FDG PET-CT after the first course of NAC.

Figure $2 \boldsymbol{a}$ and $2 \boldsymbol{b} .{ }^{18}$ Fluoro-deoxy-glucose PET-CT images of a 38 year-old woman with a low probability of BCS group: $B V_{\text {total }}=278 \mathrm{~cm}^{3}\left(\leq 496 \mathrm{~cm}^{3}\right)$ and $\triangle M T V=0 \%(\geq-17 \%)$. After NAC, she had a mastectomy. The MTV was delineated in orange while the $B V_{\text {total }}$ was delineated in blue. Figure $2 a$ illustrates ${ }^{18}$ F-FDG PET-CT before the first course of NAC NAC (the two images on the left show an axial view, the two images on the right show a sagittal view, the two images on the top show combined PET-CT scan, the two images on the bottom show CT-scan only); figure $2 b$ illustrates ${ }^{18} F$ FDG PET-CT after the first course of NAC. 


\section{Legends for tables:}

Table 1. Patient characteristics Lesion Glycolysis (TLG).

\section{Table 4. ROC Curve data.} ( $p C R$ ). of $p C R$ with ROC Curve analyses.

*The Chi-squared test was performed.

Total breast volume $\left(\mathrm{BV}_{\text {Total }}\right)$, Human epidermal growth factor receptor 2 (HER 2), Standard Uptake Value (SUV), Metabolic Tumor Volume (MTV), Total Lesion Glycolysis (TLG)

Table 2. Clinic-pathological-biological tumor characteristics according to the surgery performed. Scarff-Bloom-Richardson (SBR), Human Epidermal growth factor Receptor 2 (HER 2), 5-

Fluorouracile, Epirubicine and Cyclophosphamide (FEC), Pathological Complete Response

( $p C R)$, Fluorescent In Situ Hybridation (FISH).

$N S=$ not significant $(p>0.05) . *$ The Chi-squared test was performed .

Table 3. PET data comparison between mastectomy and breast conserving surgery groups.

Total breast volume $\left(\mathrm{BV}_{\text {Total }}\right)$, Metabolic Tumor Volume (MTV), Standard Uptake Value (SUV), Total

$N S=$ not significant $(p>0.05)$. *Mann-Whitney test was performed .

Receiver Operating Characteristic (ROC), Area Under the Curve (AUC), Standard Deviation (SD), Standard Uptake Value (SUV), Metabolic Tumor Volume (MTV), pathological Complete response

All the other ${ }^{18}$ Fluoro-deoxy-glucose PET-CT parameters evaluated were not significantly predictive

Table 5. Groups according to $\mathrm{BV}_{\mathrm{Total}}$ and tumor shrinkage (AMTV).

Total breast Volume $\left(\mathrm{BV}_{\text {Total }}\right)$, Metabolic Tumor Volume (MTV). 
$\mathbf{1 a}$
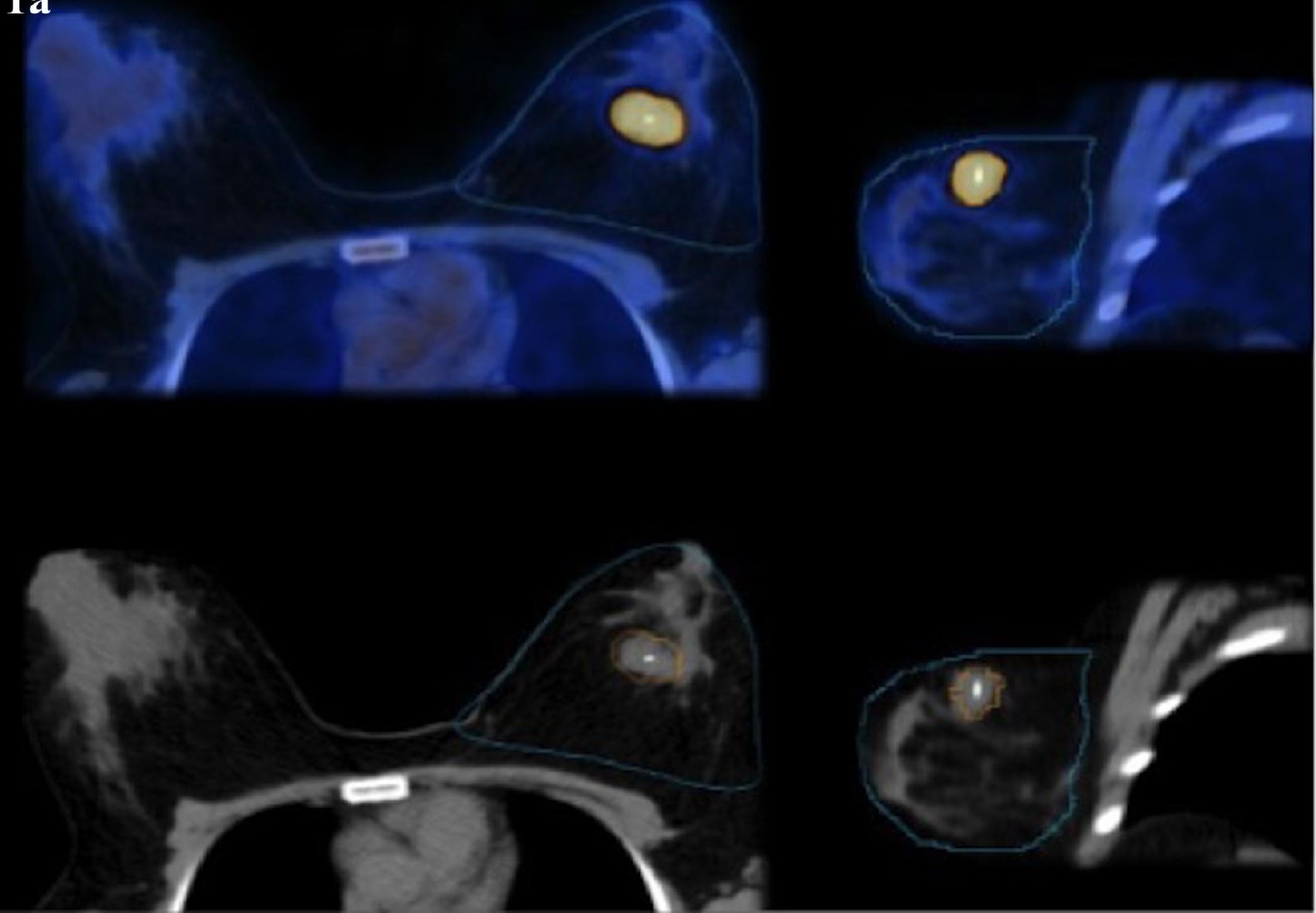
$1 b$
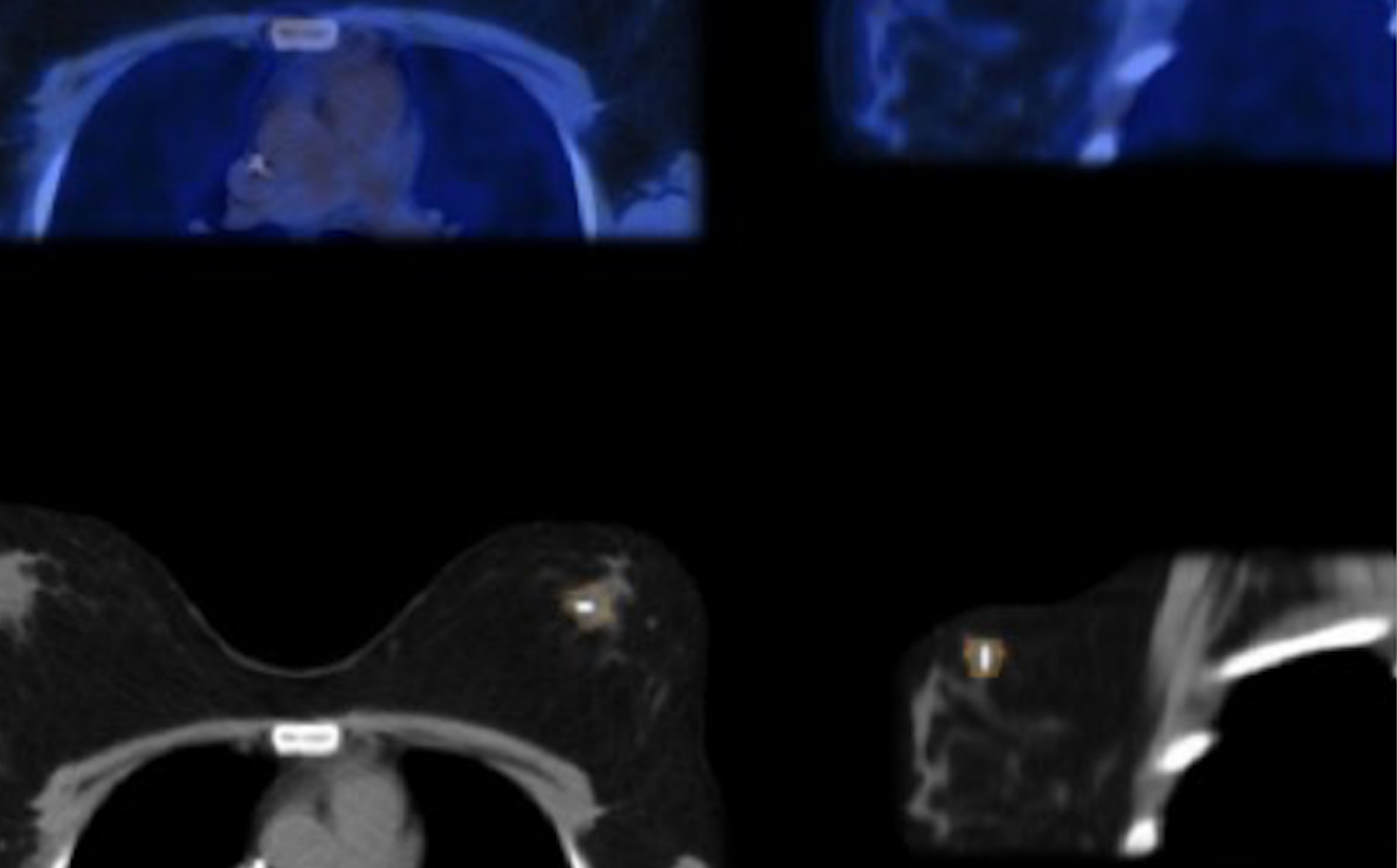
$2 b$

(2)
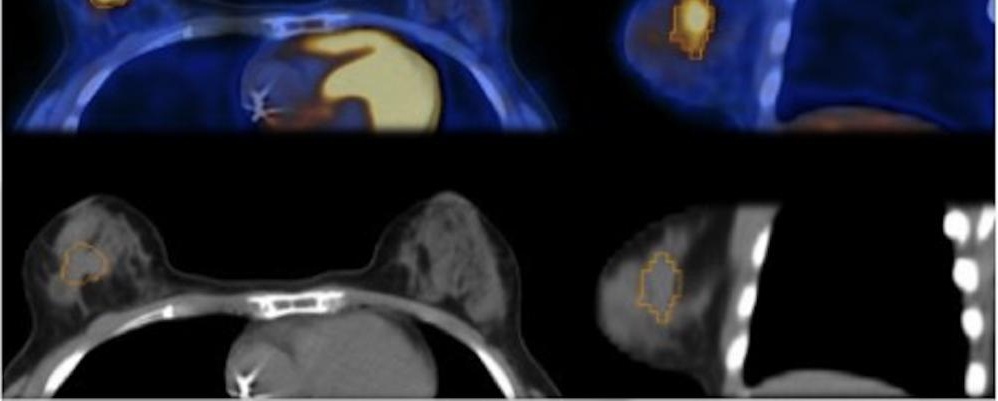
$\mathbf{2 a}$

D

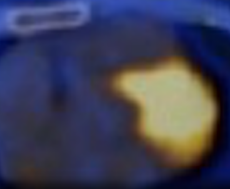

)
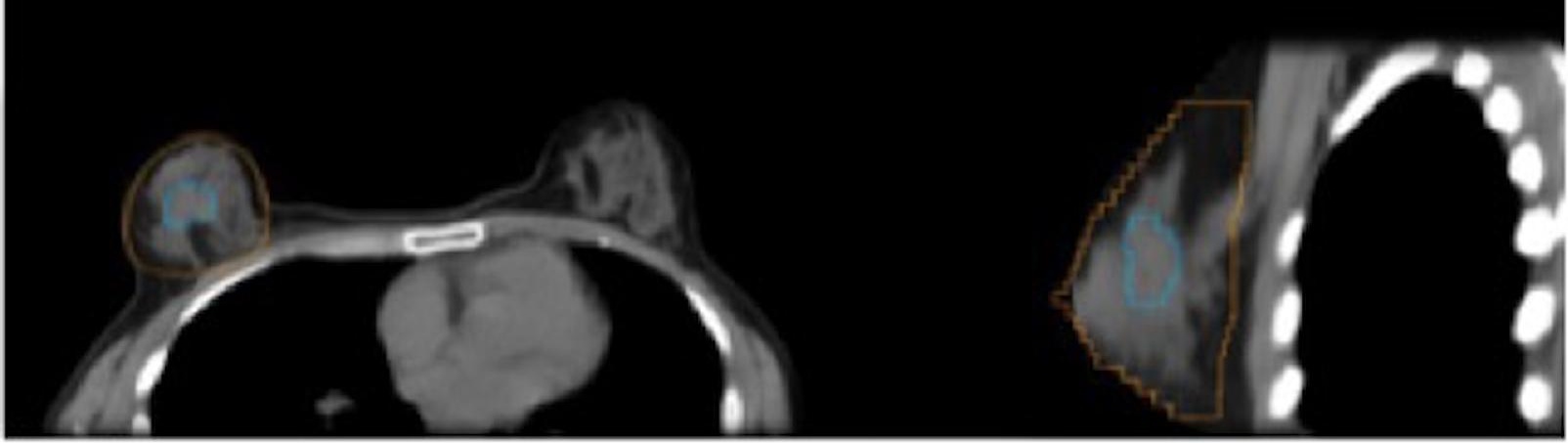


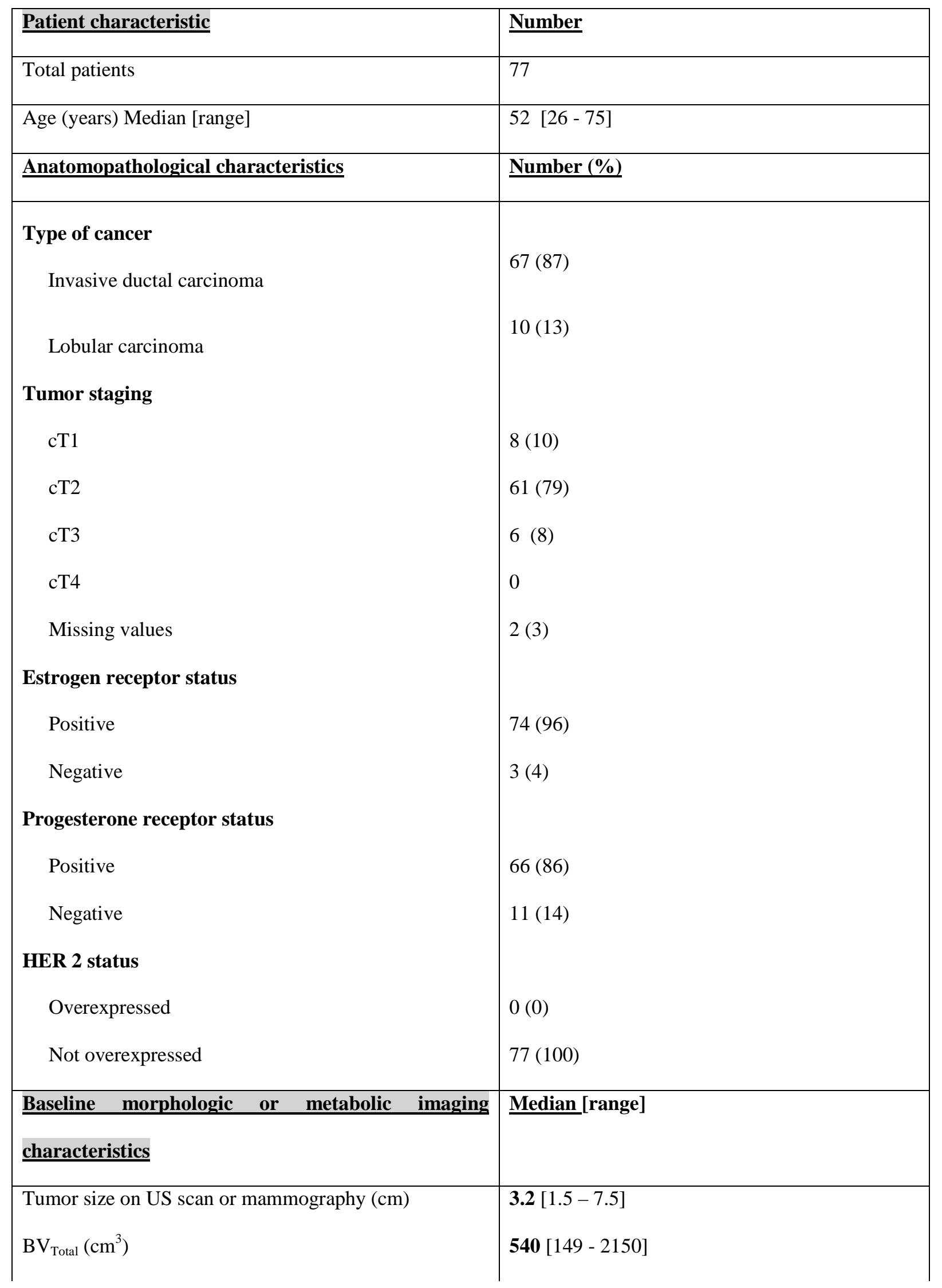




\begin{tabular}{|l|l|} 
SUVmean $_{1}$ & $\mathbf{3 . 1}[1.1-11.1]$ \\
SUVmax $_{1}$ & $\mathbf{5 . 1}[1.7-23.9]$ \\
MTV $_{1}\left(\mathrm{~cm}^{3}\right)$ & $\mathbf{6 . 7}[0.9-57.8]$ \\
$\mathrm{TLG}_{1}$ & $\mathbf{2 1 . 3}[1.7-486.7]$ \\
\hline Tumor metabolic response & $\underline{\text { Median }[\text { range }]}$ \\
$\Delta \mathrm{SUVmax}$ & $-24[-89-+101]$ \\
$\Delta \mathrm{SUVmean}$ & $-20[-86-+68]$ \\
$\Delta \mathrm{TLG}$ & $-43[-97-+37]$ \\
$\Delta \mathrm{MTV}$ & $-30[-87-+18]$ \\
\hline
\end{tabular}

\section{Table 1. Patient characteristics.}

Total breast volume ( $\left.\mathrm{BV}_{\text {Total }}\right)$, Human epidermal growth factor receptor 2 (HER 2), Standard Uptake Value (SUV), Metabolic Tumor Volume (MTV), Total Lesion Glycolysis (TLG) 


\begin{tabular}{|c|c|c|c|}
\hline & Mastectomy (\%) & $\begin{array}{l}\text { Breast } \\
\text { conserving } \\
\text { surgery }(\%)\end{array}$ & $\boldsymbol{P}^{*}$ \\
\hline $\mathbf{N}$ & $28(100)$ & $49(100)$ & \\
\hline $\begin{array}{c}\text { Age (years) } \\
\quad \leq 50 \\
>50\end{array}$ & $\begin{array}{l}15(54) \\
13(46)\end{array}$ & $\begin{array}{l}17(35) \\
32(65)\end{array}$ & $0.11 *$ \\
\hline $\begin{array}{l}\text { Tumor staging } \\
\text { cT1 } \\
\text { cT2 } \\
\text { cT3 } \\
2 \text { patients with missing values } \\
\text { were not included in } \\
\text { calculations }\end{array}$ & $\begin{array}{l}1(4) \\
22(81) \\
4(15)\end{array}$ & $\begin{array}{l}7(15) \\
39(81) \\
2(4)\end{array}$ & $0.11^{*}$ \\
\hline $\begin{array}{l}\text { Tumor location } \\
\text { External quadrants } \\
\text { Internal quadrants } \\
\text { Retro-areolar }\end{array}$ & $\begin{array}{l}21(75) \\
15(54) \\
6(21)\end{array}$ & $\begin{array}{l}39(80) \\
23(47) \\
9(18)\end{array}$ & $0.88 *$ \\
\hline $\begin{array}{l}\text { Clinical lymph node staging } \\
\text { cN0 } \\
\text { cN+ }\end{array}$ & $\begin{array}{l}9(32) \\
19(68)\end{array}$ & $\begin{array}{l}25(51) \\
24(49)\end{array}$ & $0.11^{*}$ \\
\hline $\begin{array}{c}\text { Tumor grading } \\
\text { SBR I } \\
\text { SBR II } \\
\text { SBR III }\end{array}$ & $\begin{array}{l}4(14) \\
18(64) \\
5(18)\end{array}$ & $\begin{array}{l}6(12) \\
29(59) \\
14(29)\end{array}$ & $0.62 *$ \\
\hline $\begin{array}{c}\text { Estrogen receptor status } \\
\text { Positive }\end{array}$ & $28(100)$ & $46(94)$ & $0.30^{* *}$ \\
\hline
\end{tabular}




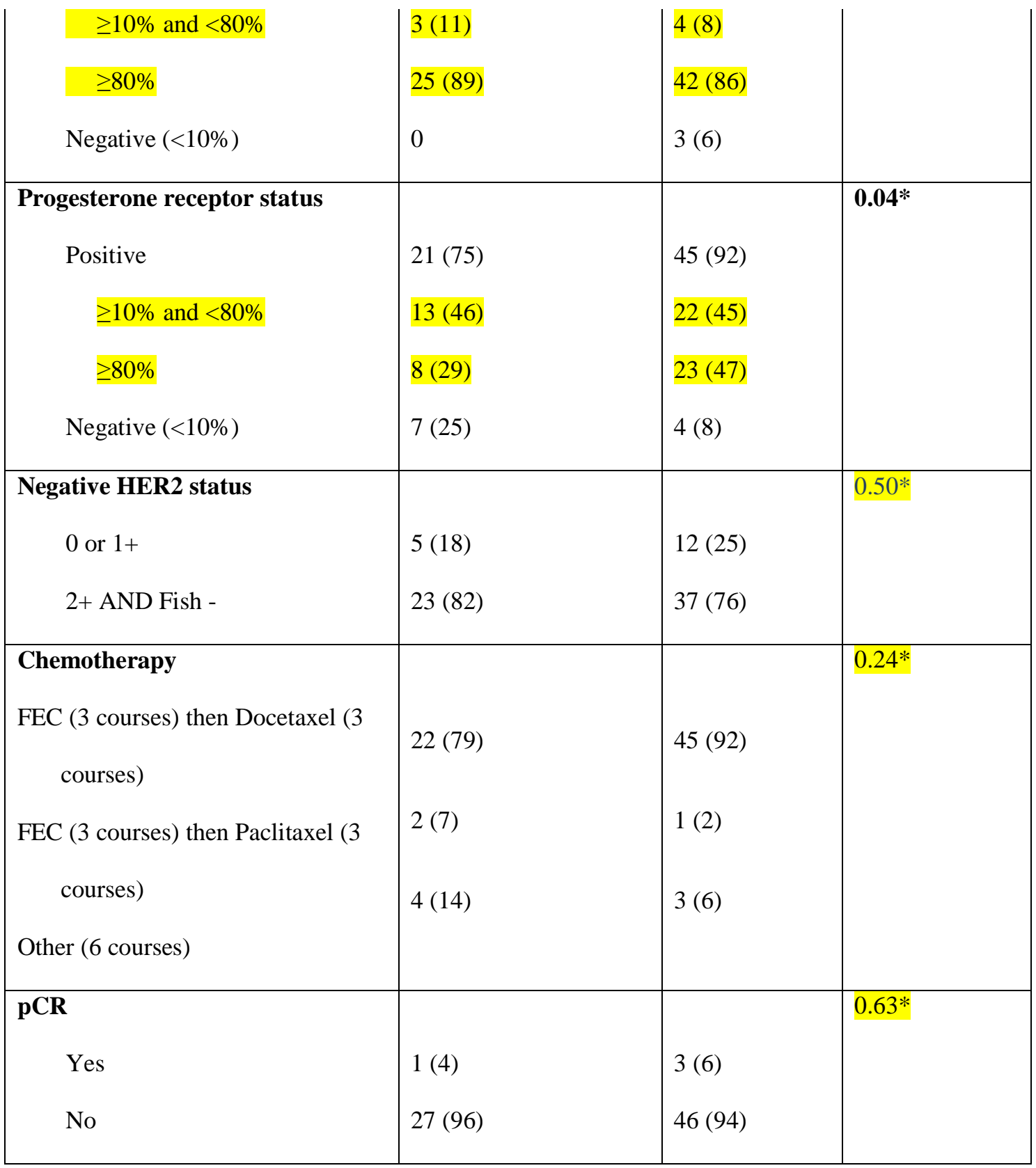

Table 2. Clinic-pathological-biological tumor characteristics according to the surgery performed.

Scarff-Bloom-Richardson (SBR), Human Epidermal growth factor Receptor 2 (HER 2), 5Fluorouracile, Epirubicine and Cyclophosphamide (FEC), Pathological Complete Response (pCR), Fluorescent In Situ Hybridation (FISH).

$N S=$ not significant $(p>0.05) . *$ The Chi-squared test, $* *$ Fisher test 


\begin{tabular}{|c|c|c|c|c|c|}
\hline & \multicolumn{2}{|c|}{$\begin{array}{l}\text { Mastectomy } \\
\text { Median [range] }\end{array}$} & \multicolumn{2}{|c|}{$\begin{array}{l}\text { Breast conserving surgery } \\
\text { Median [range] }\end{array}$} & $\boldsymbol{P}^{*}$ \\
\hline \multicolumn{6}{|c|}{ Baseline ${ }^{18}$ F-FDG PET-CT } \\
\hline $\mathbf{B} \mathbf{V}_{\text {Total }}\left(\mathrm{cm}^{3}\right)$ & 416 & {$[150-919]$} & 638 & [149 - 2150] & $<0.01$ \\
\hline $\operatorname{MTV}_{1}\left(\mathrm{~cm}^{3}\right)$ & 6.4 & {$[0.9-45.3]$} & 6.7 & {$[1.2-57.8]$} & 0.40 \\
\hline $\mathbf{M T V}_{\mathbf{1}} / \mathbf{B V}_{\text {Total }}$ & 1.1 & {$[0.4-12.8]$} & 1.11 & {$[0.2-6.1]$} & 0.59 \\
\hline $\operatorname{SUVmax}_{1}$ & 4.3 & {$[1.7-16.9]$} & 5.8 & {$[1.8-23.9]$} & 0.11 \\
\hline SUVmean $_{1}$ & 2.8 & {$[1.1-8.9]$} & 3.1 & {$[1.4-11.1]$} & 0.20 \\
\hline $\mathbf{T L G}_{1}$ & 18.6 & {$[1.7-184.8]$} & 27.0 & {$[2.1-486.7]$} & 0.26 \\
\hline \multicolumn{6}{|c|}{ Interim ${ }^{18}$ F-FDG PET-CT } \\
\hline $\mathbf{M T V}_{2}\left(\mathrm{~cm}^{3}\right)$ & 4.2 & {$[0.6-35.8]$} & 4.0 & {$[0.7-43.2]$} & 0.26 \\
\hline $\mathbf{M T V}_{2} / \mathbf{B V}_{\text {Total }}$ & 0.8 & {$[0.2-10.1]$} & 0.7 & {$[0.1-3.2]$} & 0.80 \\
\hline SUVmax $_{2}$ & 3.0 & {$[1.5-15.1]$} & 4.3 & {$[0.9-30.3]$} & 0.05 \\
\hline SUVmean $_{2}$ & 2.3 & $(1.2-8.3]$ & 2.8 & {$[0.8-9.7]$} & 0.11 \\
\hline $\mathbf{T L G}_{2}$ & 10.9 & {$[0.7-113.5]$} & 10.8 & {$[0.5-331.8]$} & 0.67 \\
\hline \multicolumn{6}{|l|}{ \% Changes } \\
\hline$\Delta \mathrm{MTV}$ & $-17 \%$ & {$[-79 \%-+18 \%]$} & $-33 \%$ & {$[-87 \%-0 \%]$} & 0.03 \\
\hline$\Delta S U V m e a n$ & $-19 \%$ & {$[-86 \%-+18 \%]$} & $-21 \%$ & {$[-73 \%-+68 \%]$} & 0.46 \\
\hline$\Delta$ TLG & $-39 \%$ & {$[-97 \%-+5 \%]$} & $-49 \%$ & {$[-95 \%-+37 \%]$} & 0.11 \\
\hline$\Delta S U V m a x$ & $-28 \%$ & {$[-89 \%-+17 \%]$} & $-24 \%$ & {$[-80 \%-+101 \%]$} & 0.93 \\
\hline
\end{tabular}

Table 3. PET data comparison between mastectomy and breast conserving surgery groups.

Total breast volume $\left(\mathrm{BV}_{\text {Total }}\right)$, Metabolic Tumor Volume (MTV), Standard Uptake Value (SUV), Total Lesion Glycolysis (TLG).

$N S=$ not significant $(p>0.05) . *$ Mann-Whitney test was performed. 


\begin{tabular}{|l|l|l|l|l|}
\hline & AUC: mean (SD) & {$[$ CI 95\% $]$} & Probability & Optimal Cut-off \\
\hline Total breast volume $\left.\mathbf{( c m}^{\mathbf{3}}\right)$ & $0.71(0.06)$ & {$[0.59-0.81]$} & $<\mathbf{0 . 0 0 1}$ & 496 \\
SUVmax & & {$[0.52-0.74]$} & $\mathbf{0 . 0 4}$ & 3.6 \\
SMTV $(\%)$ & $0.64(0.07)$ & {$[0.53-0.75]$} & $\mathbf{0 . 0 3}$ & 17.1 \\
\hline
\end{tabular}

\section{Table 4. ROC Curve data.}

Receiver Operating Characteristic (ROC), Area Under the Curve (AUC), Standard Deviation (SD), Standard Uptake Value (SUV), Metabolic Tumor Volume (MTV), pathological Complete response $(p C R)$

All the other ${ }^{18}$ Fluoro-deoxy-glucose PET-CT parameters evaluated were not significantly predictive of $p C R$ with ROC Curve analyses. 


\begin{tabular}{|c|c|c|c|c|}
\hline & $\begin{array}{l}\text { 1: Poor candidates for breast } \\
\text { conserving surgery } \\
\text { Low BV } \\
+ \text { potal } \\
+ \text { poor tumor shrinkage } \\
(\Delta \mathrm{MTV} \geq-17.1 \%)\end{array}$ & $\begin{array}{l}\text { 2: Intermediate } \\
\text { candidates for breast } \\
\text { conserving surgery } \\
\text { Neither group } 1 \text { nor } 2 \\
\end{array}$ & $\begin{array}{l}\text { 3: Good candidates for } \\
\text { breast conserving surgery } \\
\text { High BV } \\
\text { Total } \\
\text { good tumor shrinkage } \\
(\Delta \mathrm{MTV}<-17.1 \%)\end{array}$ & $\mathbf{P} *$ \\
\hline Mastectomy & $12 / 17(71 \%)$ & $10 / 26(38 \%)$ & $6 / 32(17 \%)$ & \\
\hline $\begin{array}{l}\text { Breast } \\
\text { conserving } \\
\text { surgery }\end{array}$ & $5 / 17(29 \%)$ & $16 / 26(62 \%)$ & $28 / 32(82 \%)$ & $<0.001$ \\
\hline
\end{tabular}

Table 5. Groups according to BV and tumor shrinkage (AMTV).

Total breast Volume (BV $\left.\mathrm{B}_{\text {Total }}\right)$, Metabolic Tumor Volume (MTV).

*The Chi-squared test was performed. 